JURNAL TEEKNOSAINS

\begin{tabular}{lll}
\hline VOLUME 5 & No. 1, 22 Desember 2015 Halaman 1-80
\end{tabular}

\title{
SIMULASI ALIRAN PASIEN RAWAT INAP UNTUK MENGURANGI BOTTLENECK
}

\author{
Thomas Sonny Soegiharto dan Anna Maria Sri Asih \\ Jurusan Teknik Mesin dan Industri Fakultas Teknik \\ Universitas gadjah Mada \\ Email: t.s.soegiharto@gmail.com
}

\begin{abstract}
Bottleneck is possible to occur in a system like hospital, especially in admission and discharge of inpatient processes. It can have impact on increasing waiting time and delayed time. Some alternatives were proposed to reduce them, i.e. shift scheduling and human resource allocation. This research modelled real system accompanied by two scenarios: the first scenario was conducted by balancing human resource utility without altering number of employees, whereas the second scenario considered possibility of changing number of employees. The results showed that both scenarios produced reduction of waiting time and delayed time. The first scenario is more feasible compared to the second as no hiring or firing employees occurred, resulting in waiting time reduction of 110.6 minutes (15\%) and decrease in delayed time by 184 minutes (15.9\%). The reduction of waiting time and delayed time is higher in scenario 2, which are 423.6 minutes (57\%) and 281 minutes (24\%), respectively. However, there must be 4 additional employees hired in pharmacy applied in scenario 2.
\end{abstract}

Keywords: Bottleneck; Waiting time; Delayed time; Human resource allocation; Utility, Hospital; Inpatient; Modeling; Simulation

\begin{abstract}
ABSTRAK
Inefisiensi dan bottleneck dapat terjadi di sistem rawat inap terutama pada proses pendaftaran pasien (admisi) dan proses kepulangan pasien (discharge). Pengurangan bottleneck dalam alur pasien rawat inap antara lain penjadwalan shift dan alokasi jumlah pekerja. Penelitian dilakukan dengan memodelkan sistem rawat inap sebuah rumah sakit di Yogyakarta. Model dibangun dengan 2 skenario, yaitu skenario 1 mencari solusi terbaik dengan menyeimbangkan utilitas pekerja tanpa mengubah jumlah awal karyawan dan skenario 2 melakukan penyeimbangan utilitas pekerja pula namun dengan kemungkinan perubahan jumlah pekerja. Skenario 1 merupakan solusi yang feasible karena tidak memerlukan hiring pekerja namun sudah dapat memperbaiki sistem yang ada dengan mengurangi waktu tunggu pasien sebesar 110,6 menit (15\%) dan waktu terhambat pasien sebesar 184 menit (15,9\%). Namun perbaikan yang dihasilkan skenario 1 inferior dibandingkan dengan skenario 2. Skenario 2 mampu mengurangi waktu tunggu pasien 423,6 menit (57\%) dan waktu terhambat pasien sebesar 281 menit (24\%) dengan menambah 4 petugas pada farmasi. Kedua skenario tersebut dapat menjadi pertimbangan pihak rumah sakit dengan membandingkan keuntungan dan kerugian masing-masing skenario.
\end{abstract}

Kata Kunci: Alokasi pekerja; Bottleneck; Permodelan; Rawat inap; Rumah sakit; Simulasi; Utilitas; Waktu terhambat; Waktu tunggu 


\section{PENGANTAR}

Kriteria rumah sakit yang berkualitas adalah memiliki potensi tertinggi yang mewakili regional, jumlah tempat tidur minimal sebesar 200 tempat tidur, reputasi rumah sakit di segmen pasar, kualitas pelayanan, dan potensi masa depan (Andayani, 2014). Pada objek penelitian ini, rumah sakit yang diteliti merupakan rumah sakit tipe B non pendidikan terakreditasi di provinsi DIY di mana dinyatakan lulus akreditasi tahap III untuk 16 pelayanan tercatat tanggal 8 Desember 2010 (Menteri Kesehatan, 2010 dan Kementrian Kesehatan, 2014). Rumah sakit ini memiliki spesifikasi tenaga kerja: dokter umum 26 orang, dokter spesialis 59 orang, dokter gigi 3 orang, perawat 642 orang, paramedis non perawat 122, orang non-medis 423 orang. Rumah sakit yang terakreditasi ternyata masih tidak luput dari inefisiensi kerja. Berdasarkan wawancara dengan narasumber, observasi pendahuluan, dan evaluasi laporan rekam medis, rumah sakit ini masih belum mampu memenuhi standar mutu yang ditetapkan pihak eksekutif rumah sakit.

Rumah sakit yang menjadi objek penelitian ini memiliki dua alur pasien yaitu rawat inap dan rawat jalan. Rawat inap dibandingkan dengan rawat jalan memiliki alur yang lebih panjang dan lebih rumit sehingga menimbulkan berbagai masalah, di antaranya bottleneck di dalam sistem. Faktor terjadinya bottleneck adalah bed occupancy rate (BOR) dan length of stay (LOS). BOR menunjukkan tingkat pemakaian kamar di rumah sakit. Jika BOR tinggi hampir dipastikan terjadi bottleneck di kamar, farmasi rawat inap, hingga proses kepulangan pasien. BOR yang tinggi menunjukkan jumlah pasien yang tinggi sehingga dapat terjadi penumpukan atau antrian di beberapa lokasi selain kamar. LOS menunjukkan lama tinggal pasien di rumah sakit. Lama tinggal pasien dipengaruhi oleh peningkatan kondisi kesehatan pasien dan keputusan dokter untuk memulangkan pasien. LOS yang tinggi ditambah dengan jumlah pasien yang tinggi meningkatkan kemungkinan terjadinya bottleneck. Berdasarkan wawancara dan observasi, rata-rata BOR di rumah sakit tersebut adalah $71,33 \%$ dengan kisaran 67,75\%-75,94\%. Artinya, sekitar 370 dari 440 kamar terpakai dan terjadi secara siklis. BOR mulai meninggi di bulan Januari hingga Mei kemudian menurun di bulan Juni sampai Juli. Nilai BOR yang terendah terjadi selama 2 bulan, sebelum masa lebaran. Masa pada saat lebaran bisa meningkatkan BOR karena kota Yogyakarta adalah tujuan mudik sehingga dapat memperpadat penduduk untuk sementara. Hal ini dapat menyebabkan meningkatnya BOR kembali, yang berakibat pada terjadinya bottleneck.

Waktu tunggu yang lama dan jumlah antrian yang panjang juga merupakan indikasi adanya bottleneck. Antrian panjang sering terlihat di farmasi rawat inap dan proses pendaftaran pasien yang mencakup admisi, radiologi, dan laboratorium PK. Berdasarkan observasi, waktu tunggu di farmasi berkisar 5 menit sampai 2 jam dengan ratarata 1 jam. Waktu tunggu di radiologi ratarata adalah 30 menit dengan kisaran 5 menit sampai 1,5 jam, waktu tunggu admisi hanya berkisar 30 detik sampai 21 menit dengan rata-rata 2 menit.

Di dalam farmasi, terdapat antrian yang panjang dan waktu tunggu pelayanan yang lama. Antrian di dalam farmasi rawat inap berupa kartu obat. Kartu obat datang dari masing-masing paviliun rawat inap dan waktu kedatangan sangat beragam tergantung dari jam dokter visit. Farmasi rawat inap ini melayani seluruh platform rumah sakit. Farmasi sudah menerapkan prioritas order dari ICU (Intensive Care Unit), pasien pulang, hingga pasien biasa, tetapi antrian dan waktu tunggu pelayanan masih sangat lama. Adanya antrian ini disebabkan karena jumlah pasien yang besar menyebabkan banyaknya kartu obat dan tidak seimbangnya jumlah pekerja dengan jumlah kartu obat yang akan dilayani.

Waktu pembayaran juga sering terjadi bottleneck. Pasien dapat membayar sendiri atau dengan asuransi. Pembayaran dengan asuransi memakan waktu yang lama karena 
membutuhkan konfirmasi dari 2 pihak. Proses konfirmasi ini seringkali lebih lama dari standar waktu sasaran mutu karena ada gangguan administrasi dari pihak asuransi. Masalah ini berasal dari pihak luar rumah sakit, yaitu perusahaan asuransi, maka tidak akan dilakukan perbaikan di sektor tersebut.

Pemetaan alur pasien diperlukan untuk mengetahui sumber permasalahan tersebut. Alur pasien yang buruk dapat merugikan pasien, mengurangi kepuasan pasien dan menambah biaya karena kurang efisien dalam menggunakan sumber daya karyawan (Silva, 2013). Pemetaan ini dilakukan agar dapat merepresentasikan dengan kondisi yang sebenarnya sehingga solusi tepat guna. Beberapa solusi yang dapat diberikan untuk mengurangi bottleneck adalah dengan alokasi tenaga kerja dan penjadwalan shift pekerja. Ibrahim (2011) menggunakan simulasi untuk membuat appointment scheduling dari instalasi radiologi. Dengan simulasi, didapatkan alternatif terbaik untuk interval kedatangan pasien sebesar 15 menit. Penurunan total rata-rata waktu tunggu dan senggang adalah dari 41,7 menjadi 34,68 (turun 16,83\%). Untuk alternatif lain yaitu interval 30 menit didapatkan penurunan menjadi 36,37 atau sebesar 12,78\%. Penelitian Diefenbach dan Kozan (2008) merupakan simulasi di IGD yang menggunakan Extend sebagai program permodelan dan simulasi. Hasil dari simulasi tersebut didapatkan utilitas dokter, utilitas kamar, waktu tunggu pasien, dan panjang antrian. Penelitian ini akan menggunakan simulasi dengan memakai program ProModel.

\section{Sistem dan Model}

Sistem adalah kumpulan dari beberapa entitas yang melakukan dan berinteraksi bersama-sama untuk mencapai tujuan dari sebuah logika persamaan (Schmidt dan Taylor, 1970). Fakta yang terkandung dari definisi ini antara lain sebuah sistem berupa kumpulan beberapa entitas, beraktivitas dan berinteraksi bersama-sama, dan memiliki tujuan tertentu.
Menurut Law dan Kelton (1991), definisi sistem sangat bergantung pada tujuan tinjauannya. Tujuan dari sistem harus didefinisikan secara eksplisit dan dipahami agar dapat mengolah masukan yang ada untuk mendapatkan keluaran yang diinginkan.

Model menurut Law dan Kelton (1991) adalah suatu representasi atau formulasi dalam bahasa tertentu dari suatu sistem nyata. Model berdasarkan Murthy, dkk. (1990) adalah representasi dari sistem, di mana model yang memenuhi syarat adalah model yang memenuhi tujuan dari pembuat model.

Model adalah perwakilan dari dunia nyata yang disederhanakan (Harrel, dkk., 2012). Proses atau cara operasi yang dimodelkan tidak harus persis sama karena yang penting dari model adalah bagaimana proses berdampak pada sistem, bukan pada bagaimana proses berlangsung.

\section{Simulasi}

Simulasi adalah salah satu metode yang menggunakan komputer untuk mengimitasi operasi dari berbagai macam proses maupun peralatan di dunia nyata. Simulasi merupakan salah satu riset operasi dan metode manajemen yang paling banyak digunakan secara luas [12].

Simulasi digunakan untuk mengevaluasi model secara numerik dan mengestimasi karakteristik sebenarnya dari model berdasarkan data yang didapat. States dari sebuah sistem merupakan koleksi dari berbagai variabel yang dibutuhkan untuk menjelaskan sistem di waktu-waktu tertentu (Law dan Kelton, 1991). Elemen model dalam simulasi antara lain entitas, lokasi, resource, dan paths.

\section{Uji Statistik}

1) Uji Kecukupan

Uji kecukupan data digunakan untuk menentukan bahwa jumlah sampel data yang diambil telah cukup dan mampu merepresentasikan populasinya untuk digunakan sebagai data pada proses selanjutnya. 
Pengujian dilakukan dengan menggunakan persamaan (1).

$N^{\prime}=\frac{\frac{k}{s} \sqrt{N \sum x i^{2}-\left(\sum x i\right)^{2}}}{\sum x i^{2}}$.

Uji keseragaman data dilakukan untuk mengetahui apakah populasi data sampel memiliki penyeimbangan yang normal dari nilai rata-ratanya pada tingkat kepercayaan tertentu. Pembuatan visualisasi berupa control chart dilakukan agar dapat mengetahui keseragaman data. Pada chart ditampilkan batas atas, garis tengah, dan batas bawah dengan rumus (2).

$\mathrm{UCL}=\bar{x}+3 \sigma, C L=\bar{x}, L C L=\bar{x}-3 \sigma$

\section{Verifikasi dan Validasi}

Cara verifikasi menurut Harrel, dkk. (2012) adalah review kode model, melihat animasi, memeriksa output yang masuk akal, dan menggunakan trace and debug.

Beberapa teknik validasi menurut Harrel, dkk. (2012) adalah melihat animasi, membandingkan dengan sistem nyata, membandingkan dengan model lain, melakukan tracing, melakukan face validity, dan melakukan sensitivity analysis.

Apabila tersedia data performasi sistem nyata yang cukup, maka dapat dilakukan tes statistik dengan uji statistik untuk menentukan apakah sampel data dari model dan sistem nyata mempunyai distribusi yang sama (Harrel, dkk., 2012). Apabila data sampel yang dibandingkan tidak mengikuti distribusi normal, maka menggunakan uji sampel non-parametrik. Terdapat dua macam uji dua sampel nonparametrik yaitu uji dua sampel independen dan uji dua sampel berhubungan. Salah satu contoh uji sampel independen adalah uji Mann-Whitney. Pengujian Mann-Whitney berfungsi untuk membandingkan rata-rata dua kelompok data apakah ada perbedaan yang signifikan. Hipotesis pada pengujian Mann-Whitney adalah: H0: $\mu 1=\mu 2$ dan H1: $\mu 1 \neq \mu 2$. Tabel 1 menjabarkan hipotesis alternatif dan kriteria penolakan.
Tabel 1

Hipotesis Alternatif dan Kriteria Penolakan

\begin{tabular}{l|l}
\hline Hipotesis Alternatif & Kriteria Penolakan \\
\hline$H 1: \mu_{1}{ }_{1}-\mu_{2}{ }_{2} \neq \Delta_{0}$ & $\begin{array}{l}Z_{0}>Z_{\alpha} Z_{0}>Z_{\alpha} \text { atau } \\
Z_{0}<Z_{\alpha} Z_{0}<Z_{\alpha}\end{array}$ \\
\hline$H 1: \mu_{1}{ }_{1}-\mu_{2}{ }_{2}>\Delta_{0}$ & $Z_{0}>Z_{\alpha}$ \\
\hline$H 1: \mu_{1}{ }_{1}-\mu_{2}{ }_{2}<\Delta_{0}$ & $Z_{0}<Z_{\alpha}$ \\
\hline
\end{tabular}

\section{Metode}

Pengambilan data dilakukan dengan kerjasama Instalasi Rekam Medis, IT, Bagian Administrasi Keuangan Pasien Menginap dan observasi lapangan secara langsung. Data yang sudah diambil dilakukan uji kecukupan dan uji keseragaman agar data dapat dinyatakan valid.

\section{Permodelan dan Simulasi Data}

Pembuatan model dilakukan dengan memasukkan logika dari data yang didapat. Data dimasukkan sesuai dengan pencocokan distribusi teoritis. Model yang sudah dibangun diverifikasi dan divalidasi menggunakan uji Mann-Whitney.

\section{Skenario Model}

Pada bagian ini dianalisa hasil simulasi model dan ditentukan letak permasalahan dari alur pasien dengan menggunakan dua skenario sebagai solusi dari permasalahan. Skenario pertama dengan mengubah shift dan alokasi pekerja tanpa mengubah jumlah pekerja awal dan skenario kedua dengan mencari jumlah pekerja paling optimal.

Berdasarkan laporan hasil simulasi ProModel diambil solusi terbaik dalam pengurangan bottleneck untuk menjadi rekomendasi kepada pihak manajemen rumah sakit.

\section{HASIL DAN PEMBAHASAN}

\section{Activity Cycle Diagram Model}

Alur proses pasienn rawat inap digambarkan ke dalam Actvity Cycle Diagram Model sebagaimana terlihat pada Gambar 1. 


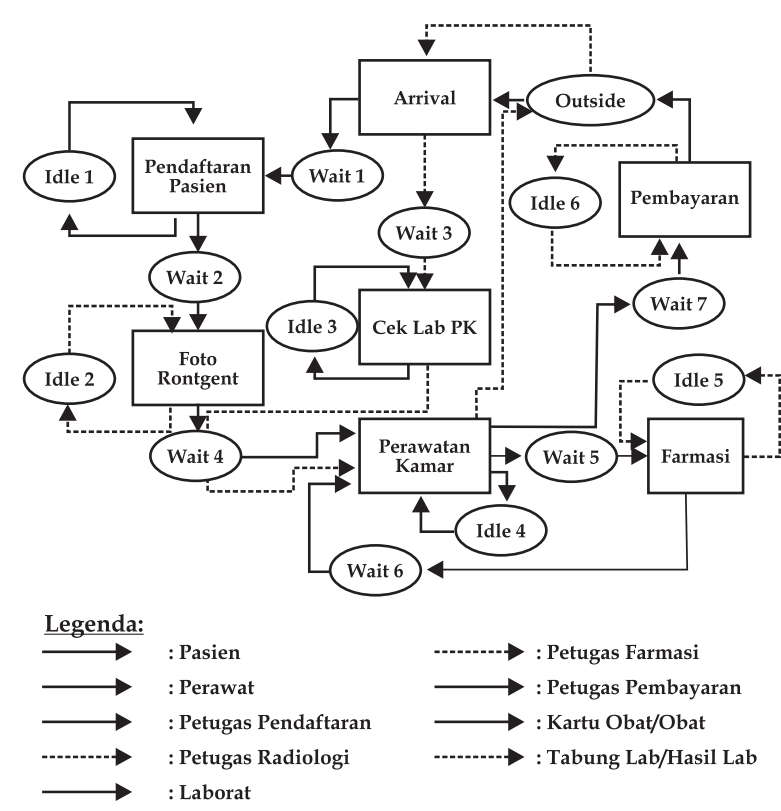

Gambar 1.

Activity Cycle Diagram Proses Rawat Inap

\section{Verifikasi dan Validasi Model}

Proses verifikasi dilakukan dengan mengecek output obat dan pasien pulang, membandingkan rata-rata lama perawatan pada entitas pasien dengan rata-rata lama perawatan pada sistem nyata. Berdasarkan asumsi bahwa setiap hari pasien memesan satu obat, maka jumlah obat akan sama dengan jumlah pasien dikalikan dengan lama perawatannya atau LOS-nya, maka perlu mencocokan keluaran obat dengan perkalian rata-rata LOS dengan keluaran pasien.

Hasil total keluaran pasien adalah sebesar 1715 orang. Rata-rata LOS (lama pasien diproses) adalah 325078 detik atau 3,76 hari. Jika dibandingkan dengan data sistem nyatanya, di mana rata-rata LOS sebesar 3,85 hari, dapat dikatakan LOS model sudah mendekati sistem nyatanya. Total masukan obat pada model adalah 6531. Perkalian LOS dengan keluaran pasien adalah 6448, dengan selisih 83 atau 0,9\%, sehingga dapat dikatakan bahwa output model sudah sesuai. Berdasarkan hal-hal tersebut dapat disimpulkan bahwa model terverifikasi.

Proses validasi perlu menggunakan uji statistik agar dapat menetapkan bahwa hasil keluaran model simulasi dengan sistem nyata tidak jauh berbeda. Uji statistik dilakukan dengan membandingkan hasil keluaran model dengan $2 / 3$ data dan model dengan $1 / 3$ data sebagai validasi model dan membandingkan hasil keluaran model simulasi dengan hasil sistem nyata sebagai validasi sistem, sehingga sampel merupakan 2 sampel yang independen yang diberi perlakuan yang sama. data tidak terdistribusi norma karena uji statistik untuk validasi tidak dapat menggunakan uji parametrik. Uji non-parametrik yang akan dilakukan adalah uji Mann-Whitney dengan $a=0,05$. Hasil yang dibandingkan adalah output pasien pulang dan waktu tunggu obat.

Uji Mann-Whitney menghasilkan Z value dan $\mathrm{p}$ value. Nilai $Z$ value untuk masingmasing uji adalah $0,367,1,69$, dan 1,077 . Nilai $\mathrm{p}$ value untuk masing-masing uji adalah $0,714,0,089$, dan 0,281 . H0 ditolak jika $Z$ value lebih besar daripada $Z a$ dan $p$ value lebih kecil daripada nilai a. Nilai semua $Z$ value lebih kecil daripada $Z a$ yaitu 1,96 dan nilai $p$ value lebih besar daripada nilai a sebesar 0,05. Sehingga dapat ditarik kesimpulan bahwa $\mathrm{HO}$ tidak dapat ditolak atau tidak ada perbedaan signifikan antara output model sistem nyata dengan data riil. Berdasarkan uraian tersebut, maka model yang dibuat dikatakan valid. Intepretasi hasil uji Mann-Whitney dapat dilihat pada Tabel 2.

Tabel 2

Interpretasi Uji Mann-Whitney

\begin{tabular}{l|l|l|l|l}
\hline \multicolumn{1}{c|}{ Uji } & \multicolumn{1}{c|}{ Z value } & p value & \multicolumn{1}{c}{ Kesimpulan } & \multicolumn{1}{c}{ Intepretasi } \\
\hline $\begin{array}{l}\text { output pasien model 2/3 data } \\
\text { dengan model 1/3 data }\end{array}$ & $0,37<1,96$ & $0,71>0,05$ & $\begin{array}{l}\mathrm{H}_{0} \text { tidak dapat } \\
\text { ditolak }\end{array}$ & $\begin{array}{l}\text { Tidak ada perbedaan } \\
\text { signifikan }\end{array}$ \\
\hline $\begin{array}{l}\text { output pasien model dengan } \\
\text { sistem nyata }\end{array}$ & $1,69<1,96$ & $0,09>0,05$ & $\begin{array}{l}\mathrm{H}_{0} \text { tidak dapat } \\
\text { ditolak }\end{array}$ & $\begin{array}{l}\text { Tidak ada perbedaan } \\
\text { signifikan }\end{array}$ \\
\hline $\begin{array}{l}\text { Waktu tunggu obat model } \\
\text { dengan sistem nyata }\end{array}$ & $1,07<1,96$ & $0,28>0,05$ & $\begin{array}{l}\mathrm{H}_{0} \text { tidak dapat } \\
\text { ditolak }\end{array}$ & $\begin{array}{l}\text { Tidak ada perbedaan } \\
\text { signifikan }\end{array}$ \\
\hline
\end{tabular}




\section{Hasil Simulasi}

Setelah model sistem nyata terverifikasi dan teruji validitasnya, maka dapat terlihat permasalahan yang terjadi di dalamnya. Masalah yang ditemui antara lain waktu tunggu dan waktu terhambat entitas pasien pulang yang mengindikasikan adanya antrian panjang seperti terlihat pada Tabel 3, serta utilitas pekerja yang tidak seimbang.

Aplikasi skenario 1 dan 2 hanya dilakukan di lokasi farmasi, radiologi, dan lab PK karena lokasi lain tidak menunjukkan perubahan yang signifikan ketika dilakukan trial and error sebelum skenario 1 dan 2 dilakukan.

Skenario 1 dilakukan dengan mencari penyeimbang utilitas pekerja. Metode yang dipakai adalah menggunakan utilitas sebagai pengali dari jumlah pekerja. Hasil perkalian dari persentase utilitas dengan jumlah pekerja akan menghasilkan alokasi jumlah pekerja per shift.

Dilakukan beberapa iterasi sampai tercapai steady state di mana utilitas dan jumlah pekerja tidak berubah walaupun sudah dilakukan dua iterasi. Terdapat delapan iterasi sebelum tercapai steady state. Skenario dua memasukkan jumlah pekerja dimulai dari satu sampai 10 orang dengan asumsi beban hiring untuk pihak rumah sakit maksimal pada 10 orang. Jumlah pekerja yang dipilih adalah yang menunjukkan utilitas seimbang, waktu tunggu minimal, dan waktu terhambat minimal dengan perubahan jumlah yang paling signifikan.

Tabel 3.

Hasil Aktivitas Entitas

\begin{tabular}{l|l|l|l|l|l}
\hline \multirow{2}{*}{ Entitas } & \multicolumn{5}{c}{ Waktu (detik) } \\
\cline { 2 - 6 } & \multicolumn{1}{|c|}{ Total } & \multicolumn{1}{c}{ Transfer } & \multicolumn{1}{c}{ Tunggu } & \multicolumn{1}{c}{ Proses } & Terhambat \\
\hline Pasien Pulang & 436841 & 521 & 44123 & 322552 & 69644 \\
\hline Obat & 5507 & 127 & 3675 & 1705 & 0 \\
\hline Hasil Lab & 6864 & 223 & 2484 & 3600 & 556 \\
\hline
\end{tabular}

Tabel 4 menunjukkan perubahan pekerja tiap iterasi untuk skenario satu. Berdasarkan Tabel 5, waktu tunggu minimal diperoleh dari skenario 1.2. Maka untuk skenario satu dipilih skenario 1.2 sebagai solusi.

Skenario dua diawali dengan mencari kombinasi dari masukan resource satu sampai 10. Kombinasi dipilih yang memberikan waktu tunggu dan waktu terhambat minimal dengan mengoptimalkan utilitas pekerja. Skenario 2 memilih solusi dari kombinasi terbaik yang diberikan oleh masing-masing lokasi. Tabel 6-8 menunjukkan hasil dari running model skenario 2. Kombinasi terbaik lokasi farmasi adalah 5-7-6, lokasi radiologi adalah 3-8-3, lokasi lab PK adalah 5-7-4. Ketiga kombinasi tersebut karena mampu mengurangi waktu terhambat dan waktu tunggu.

\section{Perbandingan Skenario}

Skenario 1 dan 2 mampu mengurangi waktu tunggu dan waktu terhambat. Skenario 1 mampu mengurangi waktu tunggu pasien pulang menjadi 37487 detik atau penurunan $15 \%$, obat menjadi 2958 detik atau 19\%, dan hasil lab menjadi 524 detik atau $78 \%$. Skenario dua dengan penambahan empat petugas farmasi mampu mengurangi waktu tunggu pasien pulang menjadi 18704 detik atau penurunan $57 \%$, obat menjadi 788 detik atau $78 \%$, dan hasil lab menjadi 74 detik atau 97\% (Tabel 9).

Skenario 1 mampu mengurangi waktu terhambat pasien pulang menjadi 58546 detik atau penurunan $16 \%$ dan hasil lab menjadi 145 detik atau $74 \%$. Skenario dua dengan penambahan empat petugas farmasi mampu mengurangi waktu terhambat pasien pulang menjadi 52782 detik atau penurunan $24 \%$ dan hasil lab menjadi 199 detik atau 64\% (Tabel 10). 
Tabel 4

Jumlah Pekerja Tiap Iterasi

\begin{tabular}{l|l|l|l|l|l|l|l|l|l}
\hline \multirow{2}{*}{ Resource } & \multicolumn{9}{c}{ Jumlah Pekerja pada iterasi ke- } \\
\cline { 2 - 11 } & \multicolumn{1}{|c|}{ Awal } & \multicolumn{1}{|c|}{$\mathbf{1}$} & $\mathbf{2}$ & $\mathbf{3}$ & $\mathbf{4}$ & $\mathbf{5}$ & $\mathbf{6}$ & 7 \\
\hline Farmasi Pagi & 6 & 4 & 4 & 4 & 4 & 4 & 4 & 4 \\
\hline Farmasi Siang & 4 & 5 & 5 & 5 & 5 & 5 & 5 & 5 \\
\hline Farmasi Malam & 4 & 5 & 5 & 5 & 5 & 5 & 5 & 5 \\
\hline Radiologi Pagi & 10 & 1 & 7 & 2 & 7 & 3 & 6 & 3 \\
\hline Radiologi Siang & 3 & 6 & 5 & 6 & 5 & 5 & 6 & 5 \\
\hline Radiologi Malam & 1 & 7 & 2 & 6 & 2 & 6 & 2 & 6 \\
\hline Lab Pagi & 10 & 2 & 8 & 3 & 7 & 3 & 6 & 4 \\
\hline Lab Siang & 4 & 7 & 6 & 6 & 7 & 5 & 8 & 5 \\
\hline Lab Malam & 2 & 7 & 2 & 7 & 2 & 8 & 2 & 7 \\
\hline
\end{tabular}

Tabel 5

Waktu Tunggu Skenario 1

\begin{tabular}{l|l|l|l|l|l}
\hline \multirow{2}{*}{ Entitas } & \multicolumn{5}{c}{ Waktu Tunggu (detik) } \\
\cline { 2 - 6 } & \multicolumn{1}{c}{ Skenario 1.1 } & Skenario 1.2 & Skenario 1.3 & Skenario 1.4 & Skenario 1.5 \\
\hline Pasien Pulang & 42816 & 37487 & 39503 & 38064 & 45336 \\
\hline Obat & 3771 & 2958 & 2837 & 3055 & 3643 \\
\hline Hasil Lab & 807 & 524 & 304 & 580 & 621 \\
\hline
\end{tabular}

Tabel 6

Waktu Tunggu Skenario 2

\begin{tabular}{l|l|l|l|l|l|l|l}
\hline \multirow{2}{*}{ Entitas } & \multirow{2}{*}{ Awal } & \multicolumn{2}{c|}{ Farmasi } & \multicolumn{2}{c|}{ Radiologi } & \multicolumn{2}{c}{ Lab PK } \\
\cline { 3 - 8 } & & \multicolumn{1}{|c|}{$\mathbf{1 0 - 6 - 7}$} & \multicolumn{1}{c}{$5-7-6$} & \multicolumn{1}{c|}{$\mathbf{4 - 7 - 3}$} & \multicolumn{1}{c}{$3-8-3$} & $4-8-4$ & $5-7-4$ \\
\hline Pasien Pulang & 44123 & 20557 & 20805 & 43949 & 46702 & 44233 & 45116 \\
\hline Obat & 3675 & 497 & 662 & 3920 & 4450 & 3744 & 4231 \\
\hline Hasil Lab & 2484 & 2617 & 2351 & 1735 & 1816 & 1792 & 1884 \\
\hline
\end{tabular}

Tabel 7.

Waktu Terhambat Skenario 2

\begin{tabular}{l|l|l|l|l|l|l|l}
\hline \multirow{2}{*}{ Entitas } & \multirow{2}{*}{ Awal } & \multicolumn{2}{c|}{ Farmasi } & \multicolumn{2}{c|}{ Radiologi } & \multicolumn{2}{c}{ Lab PK } \\
\cline { 3 - 8 } & & \multicolumn{10}{|c|}{$\mathbf{1 0 - 7}$} & $\mathbf{5 - 7 - 6}$ & $\mathbf{4 - 7 - 3}$ & $\mathbf{3 - 8 - 3}$ & $\mathbf{4 - 8 - 4}$ & \multicolumn{1}{c}{$5-7-4$} \\
\hline Pasien Pulang & 69644 & 80362 & 45825 & 74558 & 54697 & 72290 & 51677 \\
\hline Obat & 0 & 0 & 0 & 0 & 0 & 0 & 0 \\
\hline Hasil Lab & 556 & 567 & 493 & 93 & 89 & 689 & 707 \\
\hline
\end{tabular}

Tabel 8.

Hasil Skenario 2

\begin{tabular}{|c|c|c|c|c|c|c|}
\hline \multirow{2}{*}{ Resource } & \multicolumn{3}{|c|}{ Kondisi Awal } & \multicolumn{3}{|c|}{ Skenario 2} \\
\hline & Pagi & Siang & Malam & Pagi & Siang & Malam \\
\hline Petugas Farmasi & 6 & 4 & 4 & 5 & 7 & 6 \\
\hline Petugas Radiologi & 10 & 3 & 1 & 3 & 8 & 3 \\
\hline Petugas Lab PK & 10 & 4 & 2 & 5 & 7 & 4 \\
\hline
\end{tabular}


Tabel 9

Perbandingan Waktu Tunggu

\begin{tabular}{l|l|l|l}
\hline \multirow{2}{*}{ Entitas } & \multicolumn{3}{c}{ Waktu Tunggu (detik) } \\
\cline { 2 - 4 } & \multicolumn{1}{|c}{ Model Nyata } & \multicolumn{1}{c}{ Model Skenario 1 } & \multicolumn{1}{c}{ Model Skenario 2 } \\
\hline Pasien Pulang & 44123 & 37487 & 18704 \\
\hline Obat & 3675 & 2958 & 788 \\
\hline Hasil Lab & 2484 & 524 & 74 \\
\hline
\end{tabular}

Tabel 10

Perbandingan Waktu Terhambat

\begin{tabular}{l|l|l|l}
\hline \multirow{2}{*}{ Entitas } & \multicolumn{3}{c}{ Waktu Terhambat (detik) } \\
\cline { 2 - 4 } & \multicolumn{1}{|c}{ Model Nyata } & \multicolumn{1}{c}{ Model Skenario 1 } & \multicolumn{1}{c}{ Model Skenario 2 } \\
\hline Pasien Pulang & 69644 & 58546 & 52782 \\
\hline Obat & 0 & 0 & 0 \\
\hline Hasil Lab & 556 & 145 & 199 \\
\hline
\end{tabular}

\section{SIMPULAN}

Diberikan dua rekomendasi kepada pihak manajemen rumah sakit. Skenario satu sebagai solusi yang feasible karena tidak memerlukan tambahan pekerja namun sudah dapat memperbaiki sistem yang ada. Skenario dua sebagai solusi yang mencari perbaikan maksimal dengan penambahan empat pekerja farmasi. Perbaikan dari skenario dua lebih baik daripada skenario satu. Skenario dua mampu menurunkan waktu tunggu pasien sebesar $57 \%$, obat sebesar $78 \%$, dan hasil lab sebesar $98 \%$. Skenario dua lebih mampu memberikan penurunan waktu terhambat pasien sebesar $24 \%$ dan hasil lab sebesar $64 \%$.

\section{DAFTAR PUSTAKA}

Andayani, P.E., 2014, RS Peringkat Terbaik di Dunia, http://manajemenrumahsakit.net/wp-content/uploads / 2013/07/RS-Peringkat-Terbaik-diDunia.pdf, diakses online tanggal 3 September 2014.

Harrel, C., Ghosh, B.K., Bowden Jr., R.O., 2012, Simulation Using Promodel 3rd Ed., McGraw-Hill, New York.

Diefenbach, M., Kozan, E., 2008, Hospital Emergency Department Simulation for Resource Analysis, Industrial
Engineering \& Management Systems, Quennsland University of Technology, Brisbane.

Ibrahim, N., 2011, Appointment Scheduling Instalasi Radiologi dengan Metode Simulasi, Tugas Akhir Jurusan Teknik Mesin dan Industri, Universitas Gadjah Mada.

Kementerian Kesehatan RI, 2013 , List Rumah Sakit Terakreditasi Propinsi D.I.Yogyakarta, http://sirs.buk. depkes.go.id/rsonline/report/ akreditasi_list.php?id=34prop, diakses online tanggal 3 September 2014.

Law, A.M., Kelton, W.D., 1991, Simulation Modeling and Analysis 2nd Ed., McGraw-Hill, New York.

Murthy, D.N.P., Page, N.W., Rodin, E.Y., 1990, Mathematical Modelling: a Tool for Problem Solving in Engineering, Physical, Biological, and Social Sciences, Pergamon Press, UK.

Menteri Kesehatan Republik Indonesia, 2010, Peraturan Menteri Kesehatan Republik Indonesia Nomor 340 / MenKes / PER / III / 2010, Bab 4 Pasal 10-13. 
JURNAL TERKNOSAINS | VOL 5, NO. 1, DESEMBER 2015; 20-28

Schmidt, J.W., Taylor, R. E., 1970, Simulation and Analysis of Industrial Systems, Richard D. Irwin.
Silva, D.D., 2013, Improving Patient Flow Across Organisations and Pathways, The Health Foundation, Evidence Centre, London. 